\title{
Microemulsion Polymerization of Butyl Acrylate under Ultrasound Irradiation
}

\author{
Ignác CAPEK,,${ }^{1, \dagger}$ Silvia JANíčKovÁ, ${ }^{1}$ Dan Donescu, ${ }^{2}$ Yanko Sarov, ${ }^{3}$ and Ivo W. RANGelow ${ }^{3}$ \\ ${ }^{1}$ Polymer Institute, Slovak Academy of Sciences, Dúbravská cesta 9, 84236 Bratislava, Slovakia \\ ${ }^{2}$ Intitute of Chemical Research, ICECHIM, 202 Splaiul Independentei, 77208 Bucharest 6, Romania \\ ${ }^{3}$ Institute of Microtechnology and Analytics (IMA), University of Kassel, \\ Heinrich-Plett Str. 40, D-34132 Kassel, Germany
}

(Received October 6, 2005; Accepted October 28, 2005; Published March 15, 2006)

\begin{abstract}
The microemulsion polymerization (MEP) of butyl acrylate (BA) stabilized by ionic emulsifier and initiated by oil-soluble dibenzoyl peroxide (DBP) or lauroyl peroxide (LPO) initiators have been studied under conventional (without ultrasound irradiation, CMEP) and ultrasonic (NMEP) conditions. The polymerization rate vs. conversion curve of the microemulsion polymerization of BA initiated by DBP was described by two nonstationary rate intervals. Four nonstationary rate intervals with two rate maxima appear in the microemulsion polymerization of BA initiated by LPO. The maximal rate of polymerization increases with temperature and the increase is much more pronounced under the conventional conditions. The overall activation energy is much larger under the conventional conditions $\left(=84 \mathrm{~kJ} \cdot \mathrm{mol}^{-1}\right)$ than under the ultrasound $\left(=20 \mathrm{~kJ} \cdot \mathrm{mol}^{-1}\right)$ conditions. The exit (desorption) rate constants $k_{\text {des }}^{\prime}\left(\mathrm{cm}^{2} \mathrm{~s}^{-1}\right)$ and $k_{\text {des }}\left(\mathrm{s}^{-1}\right)$ (Ugelstadt/O'Tool approach, Nomura model and Gilbert model) as a function of temperature and the initiator type and concentration for the CMEP and NMEP were evaluated. Generally, the $k_{\text {des }}^{\prime}\left(\mathrm{cm}^{2} \mathrm{~s}^{-1}\right)$ slightly increase with increasing the reaction temperature (except for the highest and lowest temperatures estimated by $\left.T_{\text {model }}\right)$. The values of $k_{\text {des }}\left(\mathrm{s}^{-1}\right)$ and $k_{\text {des }}^{\prime}\left(\mathrm{cm}^{2} \mathrm{~s}^{-1}\right)$ are larger under the ultrasound conditions. The increased degradation of micellar aggregates by ultrasound irradiation is in favour of the desorption of monomeric radicals.

[DOI 10.1295/polymj.38.264]

KEY WORDS Microemulsion Polymerization / Ultrasound Irradiation / Desorption Constant / Butyl Acrylate /
\end{abstract}

The principle behind the formation of transparent or semitransparent microemulsions (fine emulsion with a droplet size $10-60 \mathrm{~nm}$ ) is the very low interfacial tension caused by the penetration of coemulsifier into the droplet surface layer. Three- or four-component mixtures containing water, monomer, emulsifier and coemulsifier can form thermodynamically stable micellar solutions (microemulsions). The addition of coemulsifier increases the thermodynamic stability of micelles driving more emulsifier into micellar state, while on the other hand it can decrease the kinetic stability of micelles leading to faster formation and dissolution of micellar aggregates in solution. The thermodynamic stability of micelles is discussed in terms of how emulsifier distributes between the monomeric emulsifier and micellar state. The kinetic stability is discussed in terms of the average time of micellar aggregate. Cosolvents (coemulsifiers) are known to penetrate into micelles. The effect of such penetrating cosolvents can be discussed in terms of two aspects: an increase in distance between emulsifier groups and a decrease in the dielectric constant of micellar layer. This can explain the decrease of CMC as a result of dilution of micellar surface charge. ${ }^{1}$
Furthermore, four-component mixtures (called miniemulsions with the droplet size $100-500 \mathrm{~nm}$ ) containing water, monomer, emulsifier and hydrophobe form mostly kinetically stable emulsions. The principle behind the making of stable miniemulsions is the introduction of a hydrophobic compound into the monomer droplets to retard the diffusion of monomer out of the monomer droplets. In both microemulsion and miniemulsion, the principal locus of particle nucleation is the emulsified monomer droplet. In the former case the dependence of the rate $v s$. conversion is described by a curve with the maximum at $c a$. 20$40 \%$ conversion and the nucleation proceeds up to the final conversion. In the latter case, the particle nucleation is somewhat shortened up to $c a$. $30-50 \%$ and the dependence of the polymerization rate of styrene $v s$. conversion can be described by a curve with two maxima (four rate intervals). ${ }^{2-4}$

The fast relaxation process is associated with the fast exchange of monomers between micelles and bulk aqueous phase. Such an exchange reflects a dynamic equilibrium between the monomeric emulsifier and the micellar state in the solution. The slow relaxation process is attributed to the micelle formation.

${ }^{\dagger}$ To whom correspondence should be addressed (E-mail: upolign@savba.sk). 
Each micellar aggregate may fluctuate in size around the vicinity of its mean value by picking up or releasing some monomers at a time as reflected from the fast relaxation process, but a complete formation and dissolution of a micelle by passing through the micelle nucleus formation steps is a much slower process than the former as reflected from the slow relaxation process. ${ }^{5}$ It is well established that the faster exchange of emulsifier ions between the micelles and the bulk solution is observed under ultrasonic conditions. ${ }^{6}$ With medium chain length alcohol (coemulsifier) this relaxation process is likely to be faster than that for emulsifier (SDS) exchange, in view of the results obtained with other alcohol/emulsifier systems. ${ }^{7}$ Therefore the ternary water/SDS/coemulsifier systems should be characterized by two exchange processes, the slow process being due to the emulsifier exchange and the fast one to the coemulsifier (alcohol) exchange. In water-rich systems, where the continuous phase is water and where the microdroplets are simply oil swollen micelles, the two observed ultrasonic relaxation processes appear. Thus, the slow process has been attributed to the exchange of emulsifier between the interfacial film and the aqueous phase (whether continuous or dispersed) whereas the fast process might be assigned to the exchange of the coemulsifier between the interfacial film and the aqueous and oil phases. Note however that the exchange is now going to occur between the droplet interfacial layer and the bulk solution. The self-association of coemulsifier (alcohol) is much more pronounced in the oil phase (w/o microdroplets). However, this process cannot be ruled out in the aqueous phase (o/w microdroplets). In the former case the association proceeds through H-bonds. ${ }^{8}$ Furthermore, the disruptive effect of ultrasound on the structure of water can lead to the increase of CMC and water solubility of hydrophobic additives and the decrease of micellar emulsifier.

The sonification initiation of emulsion polymerization and copolymerization of butyl acrylate and vinyl acetate generates efficient emulsification, a rapid polymerization at lower (room) temperature, bimodal particle size distribution, and small latex particle production at low emulsifier concentration. ${ }^{9}$ A difference in the reactivity of vinyl acetate and butyl acrylate was explained by greater evaporation of the more volatile vinyl acetate into the cavity, suppressing cavitation and reducing radicals. Small polymer particles were observed at low emulsifier concentration for butyl acrylate. This was attributed to a high radical concentration and a large number of very small monomer droplets. Vinyl acetate showed large particles. The radicals formed as a result of the ultrasonic cavitation were sufficient to initiate the polymerization. The dependence of the polymerization rate vs. conversion was described by two and four non-stationary rate intervals. The absence of interval 2 was inscribed to the continuous particle nucleation.

Some authors have noted an enhanced polymerization rate under ultrasonic conditions, ${ }^{10}$ while others stated no polymerization is observed in the absence of a chemical initiator. ${ }^{11}$ Biggs and coworkers ${ }^{9,12}$ have reported the preparation of polystyrene latex by untrasonic initiation. Vinyl acetate as well as emulsifier mixtures of the two monomers have been reacted in this way. Kruus and Patraboy ${ }^{13}$ indicated that the fractional conversion is proportional to the sonification time at low conversion. Sonochemical polymerization is initiated due to radicals produced by the thermal decomposition of monomers in or around the local hot spot. ${ }^{14}$ Furthermore, the sonolyza of water leads to the formation of $\mathrm{OH}$ and $\mathrm{H}$ radicals. In the presence of an ultrasound wave, a particle can also oscillate backward and forward because it has a different density than the surrounding aqueous phase. ${ }^{15,16}$ This oscillation is depressed because of the viscosity of the fluid, and so some of the ultrasonic energy can be converted to heat. As a result, the rate of radical formation increases. Sonochemical initiation of the emulsion polymerization was seen to cause a rapid conversion of the monomer to polymer at ambient temperatures $\left(25^{\circ} \mathrm{C}\right)$. The conversion-time behavior was seen to be analogous to that observed in microemulsion polymerization, a process of continuous nucleation also being observed. A major difference, however, was that the sonochemical process only used $2 \%$ emulsifier as compared with the $>25 \%$ in typical microemulsion polymerizations. From the data, it was concluded that the continuous supply of ultrasmall monomer droplets can act as radical traps and nucleation sites. The authors have also reported the formation of initiating radicals as a result of the ultrasonic irradiation.

In this present study we report the effect of ultrasound on the radical polymerization of butyl acrylate in fine emulsions (microemulsion). It is supposed that increased exchange rate of reaction components by ultrasound favours the "pseudo-bulk" kinetics leading to the decrease in the polymerization rate. The system chosen for investigation involves dibenzoyl peroxide (DBP) and lauroyl peroxide (LPO), two oil soluble initiators whose initiating activities are not well documented in the dispersion systems. Furthermore, LPO is know to act as a hydrophobe with the slow (or fast) exchange process between the interfacial layer and the aqueous phase (or the dispersed oil phase). The partial partitioning of DBP between oil and water phases contributes to the initiation polymerization in both phases typical for the classical micellar model. The hydrophobic nature of LPO and the location of pri- 
mary radicals in the monomer droplets are supposed to initiate the kinetic processes which deviate from those of the classical emulsion polymerization. The ultrasound irradiation is supposed to increase exchange the reaction components including the insoluble reactant and so to change the polymerization mechanism.

\section{EXPERIMENTAL}

\section{Materials}

Commercially available butyl acrylate (BA) was purified by usual methods. ${ }^{17,18}$ The analytical-grade initiators dibenzoyl peroxide (DBP) and lauroyl peroxide (LPO) were used as supplied (Fluka). The emulsifier used was the reagent-grade sodium dodecyl sulfate (SDS) (Fluka). Twice-distilled water was used as the polymerization medium.

\section{Polymerization Procedure}

The batch polymerizations were run at $50-80^{\circ} \mathrm{C}$. In all runs the recipe comprises $100 \mathrm{~g}$ water, 15 or $20 \mathrm{~g} \mathrm{BA}, 20 \mathrm{~g} \mathrm{SDS}$, and $0.025 \mathrm{~g} \mathrm{NaHCO}_{3}$. Amounts of DBP and LPO were varied as shown later. The homogenizer (Ultra Turrax, IKA Works, USA, rpm = $26,000,10 \mathrm{~min}$ ) was used to prepare the fine monomer emulsion. The fine emulsions were further homogenized with sonifier (Fisher Scientific, Sonic Dismembrator, Model 500) for $5 \mathrm{~min}$ at room temperature and then used for the dilatometric measurements. The reaction vessel of dilatometer for some experiments was inserted into the ultrasound water bath with a constant temperature. The polymerization technique, conversion determination (dilatometric and gravimetric techniques) and the estimation of polymerization rate were the same as described earlier. ${ }^{17,19,20}$

\section{Polymer and Latex Characterization}

The measurements of average particle size (a static and dynamic light scattering-LS) and the estimation of particle number were the same as described earlier. ${ }^{20,21}$ Limiting viscosity numbers $[\eta]$ were determined with Ubbelohde viscometer in acetone at $30^{\circ} \mathrm{C}$ and used to estimate the viscosity-average molecular weights. ${ }^{17,20}$

\section{SUMMARY OF BACKGROUND THEORY}

Following the theories of Harkins ${ }^{22}$ and SmithEwart $^{23}$ have produced the first quantitative model of the rate of emulsion polymerization $\left(R_{\mathrm{p}}\right)$ :

$$
R_{\mathrm{p}}=k_{\mathrm{p}}[\mathrm{M}]_{\mathrm{p}} \bar{n} N_{\mathrm{p}} / N_{\mathrm{A}}
$$

where $k_{\mathrm{p}}$ is the propagation rate constant, $[\mathrm{M}]_{\mathrm{p}}$ the equilibrium monomer concentration in the polymer particles, $\bar{n}$ the average number of radicals per particle, $N_{\mathrm{p}}$ the number of particles per unit volume of the continuous (aqueous) phase and $N_{\mathrm{A}}$ Avogardo's constant. The values of $\bar{n}$ (and so $R_{\mathrm{p}}$ ) depend on the mechanistic events such as the entry of oligomeric radicals into the particles, the nature of the reaction loci, the chain transfer to monomer, desorption of monomeric radicals and the re-entry of exited monomeric radicals.

When the "zero-one approximation" (one particle contains zero or one radical) is fulfilled then the dynamics of the quantity $\bar{n}$ is given by $\left(D_{\text {model }}\right):^{24,25}$

$$
\mathrm{d} \bar{n} / \mathrm{dt}=\rho(1-\bar{n})-\left(\rho+k_{\mathrm{des}}\right) \bar{n}
$$

where $\rho$ is the entry rate constant and $k_{\text {des }}$ the exit (desorption) rate constant. For the case of steady state $\bar{n}$ is not time dependent any more and the above derivative is equal to zero. Thus we can determine $\rho$ :

$$
\rho=k_{\operatorname{des}} \bar{n} /(1-2 \bar{n})
$$

The original approximate equation for the (monomeric) radical desorption from the polymer particles into the continuous phase proposed by Nomura et $a l^{26}$ is

$$
\begin{aligned}
& k_{\text {des }, \mathrm{N}}=\left(k_{\mathrm{mf}} / k_{\mathrm{p}}\right)\left(3 D_{\mathrm{c}} \delta / m_{\mathrm{d}} r^{2}\right) \\
& \text { where } \delta=\left(1+D_{\mathrm{c}} / m_{\mathrm{d}} D_{\mathrm{p}}\right)^{-1}
\end{aligned}
$$

or

$$
k_{\mathrm{des}, \mathrm{N}}=\left(k_{\mathrm{mf}} / k_{\mathrm{p}}\right)\left(3 D_{\mathrm{p}} / r^{2}\right) \text { when } m_{\mathrm{d}} D_{\mathrm{p}} \gg D_{\mathrm{c}},
$$

where $r$ is the particle radius, $m_{\mathrm{d}}$ the partition coefficient defined by $\left[\mathrm{M}_{\mathrm{p}}\right]=m_{\mathrm{d}}\left[\mathrm{M}_{\mathrm{c}}\right]\left(\mathrm{M}_{\mathrm{p}}\right.$ : monomeric radicals in the particle phase and $\mathrm{M}_{\mathrm{c}}$ monomeric radicals in the continuous phase) and $D_{\mathrm{c}}$ and $D_{\mathrm{p}}$ the diffusion coefficients of monomeric radicals in the continuous and particle phases, respectively. This approach is valid for the emulsion polymerization initiated by the continuous-phase initiated polymerization (the initiator starts to decompose and form primary radicals in the continuous phase). At the steady state, the overall rate of radical entry into the particles is given by the sum of the rates of radical production in the water phase and radical desorption from the polymer particles minus the rate of radical termination in the aqueous phase. The specific desorption rate constant $k_{\text {des }}\left(\mathrm{s}^{-1}\right)$ is related to $k_{\text {des }}^{\prime}\left(\mathrm{cm}^{2} \mathrm{~s}^{-1}\right)$ by the following equations: ${ }^{27}$

$$
k_{\text {des }} a_{\mathrm{p}} / v_{\mathrm{p}}=k_{\text {des }}^{\prime} /\left[(\pi / 6)^{2 / 3} D_{\mathrm{p}}^{2}\right]
$$

where $d_{\mathrm{p}}$ is the diameter of a monomer-swollen particle, $v_{\mathrm{p}}$ the volume of monomer-swollen particles and $a_{\mathrm{p}}$ the surface area of a monomer-swollen particle. The parameter $k_{\text {des }}^{\prime}$ is independent of particle size and, therefore, it is reasonable to compare $k_{\text {des }}^{\prime}$ with the literature ones. In the Nomura model $\left(\mathrm{N}_{\text {model }}\right)$ 
desorption of monomeric radicals is related to the particle size and the partitioning coefficient. The dependence of the desorption rate of radicals on the rate of polymerization, the number of radicals per particle and the number of particles is modeled by O'Toole. ${ }^{28}$ The experimental values of $d_{\mathrm{p}}, N_{\mathrm{p}}$ and $\bar{n}$ were used to estimate the exit of radicals from the polymer particles through the iterative approach comparing the experimental with theoretical $\bar{n}_{\text {theor values: }}:^{28}$

$$
\bar{n}_{\text {theor }}=a^{\prime} / 4\left[I_{m}\left(a^{\prime}\right) / I_{m-1}\left(a^{\prime}\right)\right]
$$

where $a^{\prime}=(8 \mathrm{a})^{0.5}, I_{m}$ and $I_{m-1}$ are the Bessel functions of the first kind of order $m$ and $m-1$, respectively. The kinetic parameters $a=\rho_{\mathrm{a}} v_{\mathrm{p}} / k_{\mathrm{t}} N_{\mathrm{p}}$ and $m=$ $k_{\text {des }} a_{\mathrm{p}} / k_{\mathrm{t}}$ are the dimensionless parameters related to adsorption of free radicals by polymer particles and desorption of radicals out of the particles, respectively. The symbol $\rho_{\mathrm{a}}$ is the absorption rate of radicals by the particles and $k_{\mathrm{t}}$ is the termination rate constant in the particle. Ugelstad and coworkers ${ }^{29}$ took into account the termination reaction in the aqueous phase and reabsorption of desorbed radicals by the particles and developed the following relationship:

$$
a=a_{1}+m \bar{n}-\mathrm{Y} a^{2}
$$

where $a_{1}=\rho_{\mathrm{i}} v_{\mathrm{p}} / k_{\mathrm{t}} N_{\mathrm{p}}$ and $\mathrm{Y}=2 N_{\mathrm{a}} k_{\mathrm{tw}} k_{\mathrm{t}} / k_{\mathrm{c}}{ }^{2} v_{\mathrm{p}} N_{\mathrm{p}}$ are the dimensionless groups related to the generation of initiator radicals in water and termination of radicals in the aqueous phase, respectively. The parameters $k_{\mathrm{tw}}$ and $k_{\mathrm{c}}$ represent the termination rate constant in the aqueous phase and rate constant for the capture of radicals by the particles, respectively, and $\rho_{\mathrm{i}}$ is the rate of initiation.

With the assumption that termination in the aqueous phase is not important (i.e., $\mathrm{Y}=0$ ), a (or $\rho_{\mathrm{a}}$ ) and $m$ (or $\left.k_{\text {des,T }}\right)$ can be calculated as $\left(T_{\text {model }}\right),{ }^{30}$

1) Guess $a$ value for $m$

2) Compute $a$ according to eq 8

3) Compute $\bar{n}_{\text {theor }}$ by eq 7

4) If calculated $\bar{n}_{\text {theor }}$ is equal to the experimental value, accept the theoretical values of $a$ and $m$. If not, go back to step 1.

5) Compute $\rho_{\mathrm{a}}=a k_{\mathrm{t}} N_{\mathrm{p}} / v_{\mathrm{p}}$ and $k_{\mathrm{des}, \mathrm{T}}=m k_{\mathrm{t}} / a_{\mathrm{p}}$.

\section{RESULTS AND DISCUSSION}

\section{Rate of Polymerization}

In the dibenzoyl peroxide (DBP)-initiated microemulsion polymerization of $\mathrm{BA}$, the polymerization rate increases to a maximum ( $\mathrm{ca}$. at 20-30\%) followed by a final decrease (the two-rate intervals). ${ }^{19,20}$ The kinetic and colloidal data of the DBP-initiated microemulsion polymerization without and under ultrasound irradiation are summarized in Figures 1 and 2 , Tables I and II. The polymerization rate vs. con-

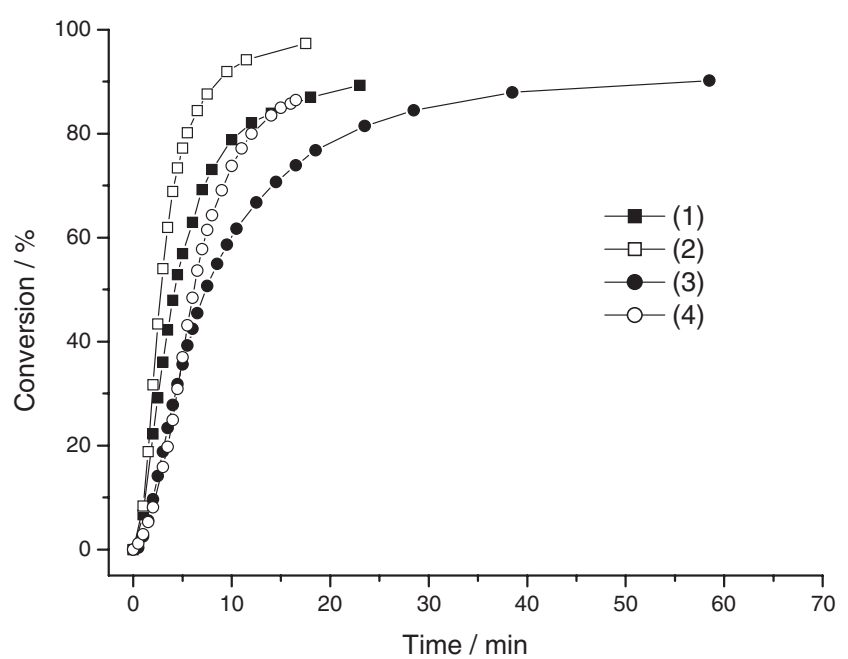

Figure 1. Variation of the monomer conversion with reaction time and DBP concentration of microemulsion polymerization of BA initiated by dibenzoyl peroxide (DBP). Recipe, $c f$. Experimental. $[\mathrm{BA}]=1.56 \mathrm{~mol} \mathrm{dm}{ }^{-3}$; temp. $=60^{\circ} \mathrm{C} ; \quad[\mathrm{DBP}] / \mathrm{mol} \cdot \mathrm{dm}^{-3}$ : 2.5 /without ultrasound (1), 10.0/without ultrasound (2), 2.5/with ultrasound (3), 10.0/with ultrasound (4).

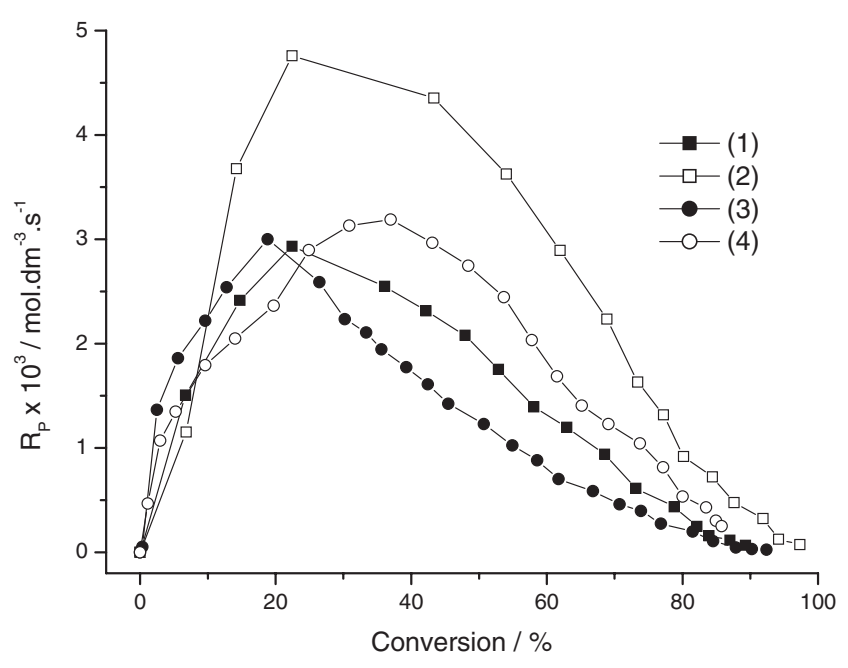

Figure 2. Variation of the rate of microemulsion polymerization of BA initiated by DBP with conversion and initiator concentration. Recipe, $c f$. Experimental. $[\mathrm{BA}]=1.56 \mathrm{~mol} \mathrm{dm}^{-3}$; temp. $=$ $60^{\circ} \mathrm{C}$; [DBP $] / \mathrm{mol} \cdot \mathrm{dm}^{-3}: 2.5 /$ without ultrasound (1), $10.0 /$ without ultrasound (2), 2.5/with ultrasound (3), 10.0/with ultrasound (4).

version curve of the microemulsion polymerization of BA initiated by DBP was described by two nonstationary rate intervals. The appearance of maximal rates can be the result of two opposing effects; 1) the increase of number of polymer particles and 2) the decrease of monomer concentration with increasing conversion. The first abrupt increase in the rate of polymerization is attributed to the intensive particle nucleation and the polymerization under monomer saturation conditions. ${ }^{17}$ The monomer saturation conditions are operative below $c a .20 \%$ conversion. This is one of reasons why the abrupt increase in the initial 
Table I. Variation of kinetic, molecular weight and colloidal parameters in the microemulsion polymerization of BA with $[\mathrm{DBP}]^{\mathrm{a}}$

\begin{tabular}{clcccccc}
\hline $\begin{array}{c}{[\mathrm{DBP}] 10^{3}} \\
\left(\mathrm{~mol} \cdot \mathrm{dm}^{-3}\right)\end{array}$ & $\begin{array}{c}R_{\mathrm{p}, \max } 10^{3} / \mathrm{Conv} \cdot \max \\
\left(\mathrm{mol} \cdot \mathrm{dm}^{-3} \cdot \mathrm{s}^{-1}\right) /(\%) \\
1)\end{array}$ & $\begin{array}{c}\mathrm{Conv}_{\cdot f} \\
(\%)\end{array}$ & $\begin{array}{c}D \\
(\mathrm{~nm})\end{array}$ & $\begin{array}{c}N_{\mathrm{p}} \times 10^{-17} \\
\left(\mathrm{dm}^{3}\right)\end{array}$ & $M_{\mathrm{v}} \times 10^{-6}$ & $\begin{array}{c}\bar{n} \times 10^{2} \\
\left(\mathrm{particle}^{-1}\right)\end{array}$ \\
\hline $0.71^{\mathrm{b}}$ & $0.87 / 15$ & & 86 & 81 & 4.5 & 2.9 & 1.9 \\
$1.0^{\mathrm{b}}$ & $0.7 / 15$ & & 88 & 80 & 4.8 & 2.5 & 1.4 \\
$10.0^{\mathrm{b}}$ & $2.0 / 10$ & & 91 & 70 & 7.4 & 2.3 & 2.5 \\
$0.71^{\mathrm{c}}$ & $3.0 / 18$ & $2.2 / 42$ & 87 & 70 & 7.0 & 2.6 & 4.0 \\
$1.0^{\mathrm{c}}$ & $2.0 / 23$ & $0.7 / 38$ & 85 & 71 & 6.6 & 2.6 & 3.0 \\
$2.5^{\mathrm{c}}$ & $1.7 / 23$ & & 91 & 76 & 5.8 & 2.4 & 2.9 \\
$10.0^{\mathrm{c}}$ & $1.3 / 25$ & & 87 & 79 & 4.9 & 2.2 & 2.6 \\
\hline
\end{tabular}

${ }^{\mathrm{a}}$ Recipe $c f$. Exptl. part. $[\mathrm{BA}]=1.17 \mathrm{~mol} \cdot \mathrm{dm}^{-3}, 60{ }^{\circ} \mathrm{C}$. ${ }^{\mathrm{b}}$ Without ultrasound irradiation, ${ }^{\mathrm{c}}$ with ultrasound irradiation.

Table II. Variation of kinetic, molecular weight and colloidal parameters in the microemulsion polymerization of BA with $[\mathrm{DBP}]^{\mathrm{a}}$

\begin{tabular}{ccccccc}
\hline $\begin{array}{c}{[\mathrm{DBP}] 10^{3}} \\
\left(\mathrm{~mol} \cdot \mathrm{dm}^{-3}\right)\end{array}$ & $\begin{array}{c}R_{\mathrm{p}, \max } 10^{3} / \mathrm{Conv} \cdot \max \\
\left(\mathrm{mol} \cdot \mathrm{dm}^{-3} \cdot \mathrm{s}^{-1}\right) /(\%)\end{array}$ & $\begin{array}{c}\text { Conv.f } \\
(\%)\end{array}$ & $\begin{array}{c}D \\
(\mathrm{~nm})\end{array}$ & $\begin{array}{c}N_{\mathrm{p}} \times 10^{-17} \\
\left(\mathrm{dm}^{3}\right)\end{array}$ & $M_{\mathrm{v}} \times 10^{-6}$ & $\begin{array}{c}\bar{n} \times 10^{2} \\
\left(\mathrm{particle}^{-1}\right)\end{array}$ \\
\hline $1.0^{\mathrm{b}}$ & $2.0 / 20$ & 93 & 86 & 5.4 & 2.6 & 3.6 \\
$2.5^{\mathrm{b}}$ & $3.0 / 21$ & 89 & 83 & 5.8 & 2.3 & 5.1 \\
$10.0^{\mathrm{b}}$ & $4.75 / 22$ & 97 & 80 & 7.0 & 2.1 & 6.6 \\
$1.0^{\mathrm{c}}$ & $2.44 / 15$ & 96 & 90 & 4.9 & 2.5 & 4.9 \\
$2.5^{\mathrm{c}}$ & $3.0 / 18$ & 91 & 88 & 5.0 & 2.4 & 5.9 \\
$10.0^{\mathrm{c}}$ & $3.2 / 37$ & 87 & 86 & 5.1 & 2.3 & 6.2 \\
\hline
\end{tabular}

${ }^{\text {a}}$ Recipe $c f$. Exptl. part. $[\mathrm{BA}]=1.56 \mathrm{~mol} \cdot \mathrm{dm}^{-3},{ }^{\mathrm{b}}$ Without ultrasound irradiation, ${ }^{\mathrm{c}}$ with ultrasound irradiation.

rate appears. On the other hand, the monomer-starved conditions are operative beyond $c a .30 \%$ conversion and therefore the rate of polymerization decreases with increasing conversion. The larger the particle number, the lower the monomer concentration at the reaction loci. ${ }^{31}$

Variations of monomer conversion with the reaction time in the microemulsion polymerization of BA initiated by lauroyl peroxide (LPO) are summarized in Figures 3 and 5. Variations of polymerization rate with conversion, temperature and the concentration of reactants are summarized in Figures 4 and 6 and Tables III-V. The microemulsion polymerization of BA was initiated by LPO without (conventional microemulsion polymerization-CMEP) (Tables III and V, Figures 3 and 4) and under the ultrasound (nonconventional microemulsion polymerization-NMEP) irradiation (Tables IV and V, Figures 5 and 6). The dependence of the rate of polymerization $v s$. conversion in both CMEP and NMEP is described by a curve with two maxima (four rate intervals). This behavior is very similar to that observed in the miniemulsion polymerization of styrene or methyl methacrylate in the presence of hydrophobe (hexadecane, cetyl alcohol, LPO, hydrophobic polymer, etc. ${ }^{2-4}$ and that observed in the emulsion polymerization of $\mathrm{BA}$ and vinyl acetate under ultrasound irradiation. ${ }^{9}$

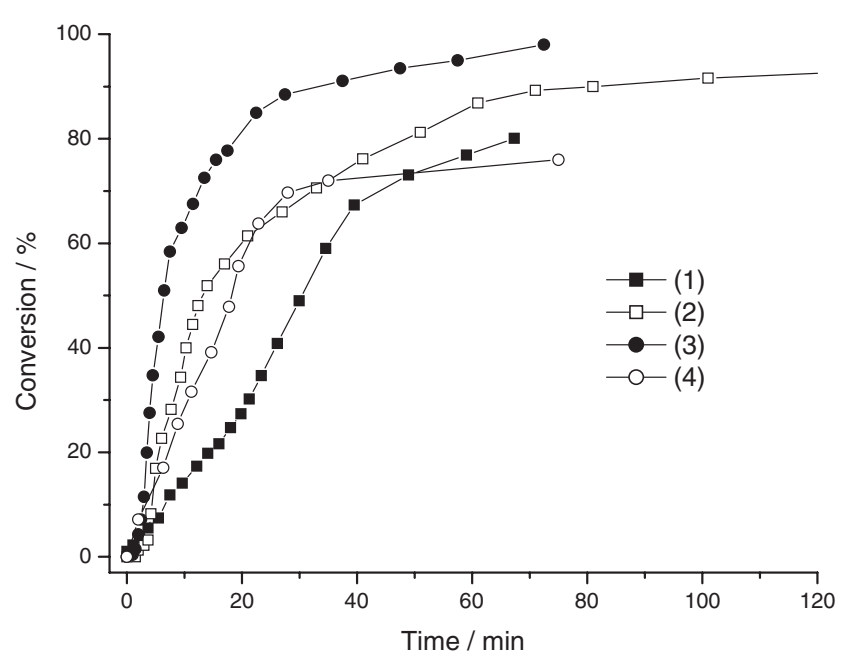

Figure 3. Variation of the monomer conversion with reaction time and temperature of microemulsion polymerization of butyl acrylate (BA) initiated by lauroyl peroxide (LPO), without ultrasound irradiation. Recipe, $c f$. Experimental. $[\mathrm{LPO}]=1.10^{-2}$ $\mathrm{mol} \cdot \mathrm{dm}^{-3},[\mathrm{BA}]=1.56 \mathrm{~mol} \mathrm{dm}{ }^{-3}$; temperature $/{ }^{\circ} \mathrm{C}: 50$ (1), 60 (2), 70 (3), 80 (4).

The DBP-initiated microemulsion polymerization of BA differs from that found for LPO-initiated polymerization where the four-rate intervals were observed. The accumulation of polar polymer (PBA) itself does not promotes the gel effect. The presence 


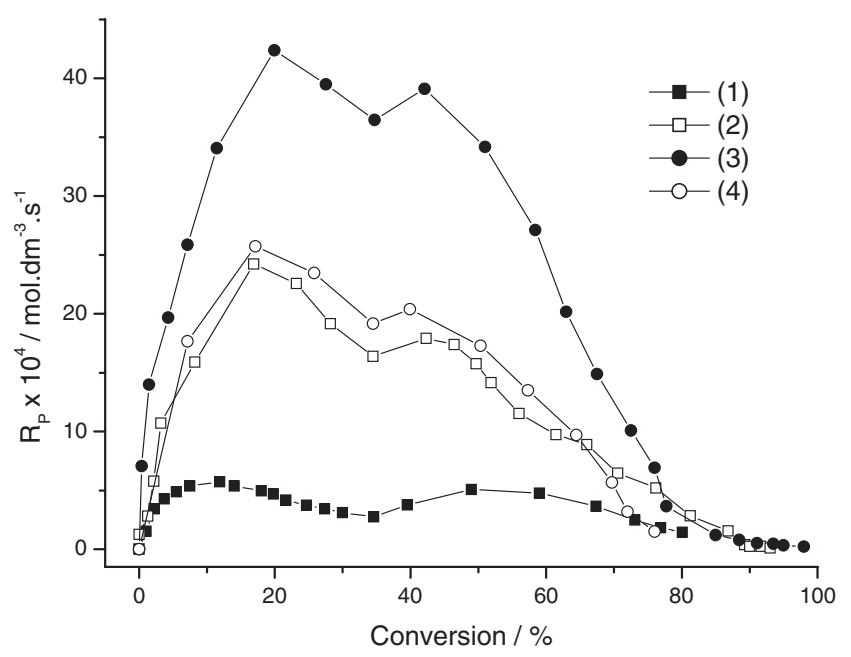

Figure 4. Variation of the rate of microemulsion polymerization of BA initiated by LPO with conversion and temperature, without ultrasound irradiation. Recipe, $c f$. Experimental. [LPO] $=$ $1.10^{-2} \mathrm{~mol} \cdot \mathrm{dm}^{-3}, \quad[\mathrm{BA}]=1.56 \mathrm{~mol} \mathrm{dm}{ }^{-3} ;$ temperature $/{ }^{\circ} \mathrm{C}: 50$ (1), 60 (2), 70 (3), 80 (4).

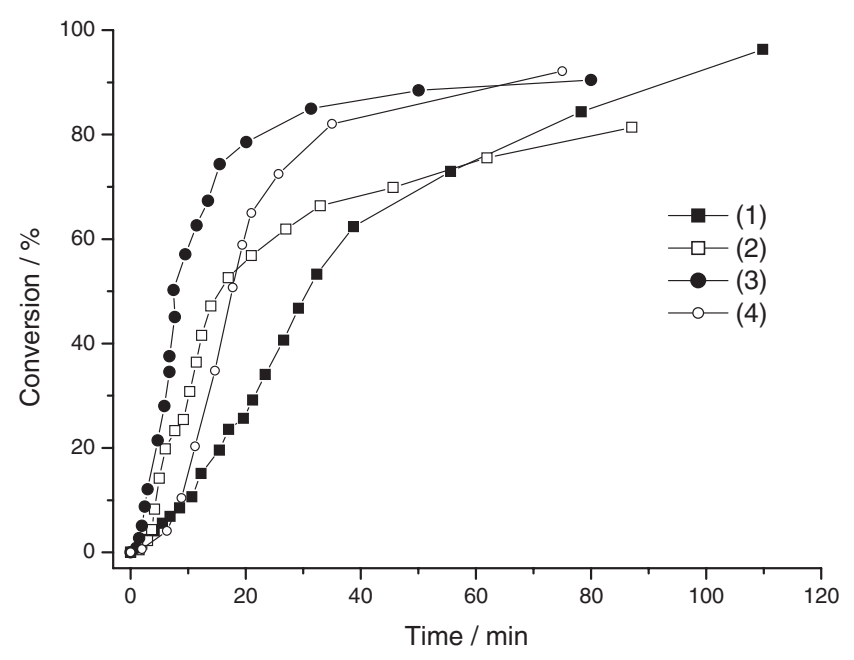

Figure 5. Variation of the monomer conversion with reaction time and temperature of microemulsion polymerization of butyl acrylate (BA) initiated by lauroyl peroxide (LPO), with ultrasound irradiation. Recipe, $c f$. Experimental. $[\mathrm{LPO}]=1.10^{-2} \mathrm{~mol} \cdot \mathrm{dm}^{-3}$, $[\mathrm{BA}]=1.56 \mathrm{~mol} \mathrm{dm}{ }^{-3}$; temperature $/{ }^{\circ} \mathrm{C}: 50$ (1), 60 (2), 65 (3), 70 (4).

of large number of microdroplets $\left(\mathrm{ca} \cdot 10^{21}\right.$ per $\left.\mathrm{dm}^{3}\right)$ promotes the continuous nucleation of polymer particles up to high conversion. ${ }^{2}$ It has been shown by thermodynamics that the concentration of monomer will decrease throughout the polymerization, and that monomer in fine (micro- or mini) droplets may exist throughout the polymerization. ${ }^{32}$ As a result, the polymerization rate may reach a maximum prior to the end of the nucleation period if the rate of formation of polymer particles slows down enough that decreasing concentration of monomer in the particles dominates the rate of polymerization. The decrease of the rate

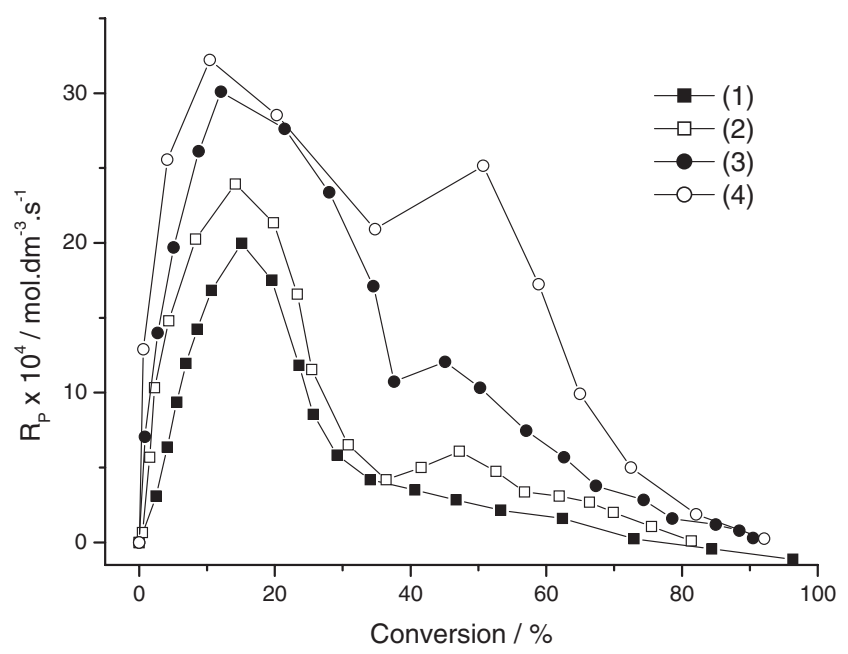

Figure 6. Variation of the rate of microemulsion polymerization of BA initiated by LPO with conversion and temperature, with ultrasound irradiation. Recipe, $c f$. Experimental. [LPO] $=$ $1.10^{-2} \mathrm{~mol} \cdot \mathrm{dm}^{-3}, \quad[\mathrm{BA}]=1.56 \mathrm{~mol} \mathrm{dm}{ }^{-3} ;$ temperature $/{ }^{\circ} \mathrm{C}: 50$ (1), 60 (2), 65 (3), 70 (4).

of polymerization due to the decrease of monomer concentration in the polymer particles was experimentally proved in the microemulsion polymerization of butyl acrylate. ${ }^{20}$

The presence of polymer in droplets (highly monomer swollen particles) can reduce the monomer transport rate in the reaction system and increase the nucleation interval. ${ }^{33}$ The presence of LPO and continuous accumulation of hydrophobic oligomers promote the formation of highly monomer swollen particles and additional reaction loci. The observed behavior is very similar to that reported by El-Aasser et al. ${ }^{29}$ and Shork et $a l .{ }^{34}$ for the classical miniemulsion polymerizations of styrene and MMA in the presence of low and high molecular weight hydrophobe such as hexadecane (HD), polymer, etc. and homogenized by a uniform shear device. In the classical miniemulsion polymerizations using an effective hydrophobe (HD) the second maximum is more pronounced. ${ }^{35}$

The rate of CMEP of BA initiated by LPO first increases with temperature from 50 to $75^{\circ} \mathrm{C}$ and then decreases (Table IV). The rate of initiation $\left(\rho_{\mathrm{i}}=2 f k_{\mathrm{d}}\right.$ [I], where $f$ is the initiation efficiency $(0.5), k_{\mathrm{d}}$ is the decomposition rate of initiator and [I] is the concentration of initiator), however, increases with temperature in the whole temperature range:

$$
\begin{aligned}
& \rho_{\mathrm{i}} \times 10^{8}\left(\mathrm{~mol} \cdot \mathrm{dm}^{-3} \cdot \mathrm{s}^{-1}\right) / \text { temp. }\left({ }^{\circ} \mathrm{C}\right) \\
& =3.5 / 50,8.4 / 55,15.5 / 60,27.7 / 65,48.7 / 70,117 / 75
\end{aligned}
$$

The decrease in the polymerization rate above 70 or $75^{\circ} \mathrm{C}$ can be attributed to the primary radical termination and the partial destabilization of polymer particles both leading to the decrease in the final number of polymer particles. The similar behavior was also 


\section{CAPEK et al.}

Table III. Kinetic, molecular weight and colloidal parameters in the emulsion polymerization of BA (without ultrasound irradiation) ${ }^{\mathrm{a}}$

\begin{tabular}{|c|c|c|c|c|c|c|c|c|c|}
\hline \multirow[t]{2}{*}{$\begin{array}{l}\text { Temp. } \\
\left({ }^{\circ} \mathrm{C}\right)\end{array}$} & \multicolumn{2}{|c|}{$\begin{array}{l}R_{\mathrm{p}, \max } \times 10^{3} / \mathrm{Conv}_{\cdot R \mathrm{p}, \max } \\
\quad\left(\mathrm{mol} \cdot \mathrm{dm}^{-3} \cdot \mathrm{s}^{-1}\right) /(\%)\end{array}$} & \multirow[t]{2}{*}{$\begin{array}{c}\text { Conv.f } \\
(\%)\end{array}$} & \multicolumn{2}{|c|}{$\begin{array}{c}D \\
(\mathrm{~nm})\end{array}$} & \multicolumn{2}{|c|}{$\begin{array}{l}N_{\mathrm{p}} 10^{-17} \\
\left(\mathrm{dm}^{3}\right)\end{array}$} & \multirow[t]{2}{*}{$M_{\mathrm{v}} \times 10^{-6}$} & \multirow[t]{2}{*}{$\begin{array}{c}\bar{n} \times 10^{2} \\
\left(\text { particle }^{-1}\right)\end{array}$} \\
\hline & 1) & 2) & & 3) & 4) & 3) & 4) & & \\
\hline 50 & $0.6 / 11$ & $0.5 / 50$ & 80 & 95 & 300 & 2.9 & 0.02 & 2.8 & 1.9 \\
\hline 55 & $1.5 / 15$ & $1.1 / 45$ & 85 & 87 & 350 & 4.4 & 0.01 & 2.3 & 3.2 \\
\hline 60 & $2.4 / 17$ & $1.7 / 42$ & 93 & 85 & 300 & 4.5 & 0.02 & 2.4 & 4.2 \\
\hline 65 & $3.5 / 20$ & $2.8 / 43$ & 79 & 80 & 280 & 4.6 & 0.03 & 2.1 & 5.6 \\
\hline 70 & $4.2 / 20$ & $3.9 / 42$ & 98 & 70 & 250 & 9.4 & 0.03 & 2.0 & 3.5 \\
\hline 75 & $6.5 / 23$ & $5.1 / 41$ & 89 & 60 & 200 & 12.2 & 0.08 & 1.5 & 3.6 \\
\hline 80 & $2.5 / 17$ & $2.0 / 40$ & 76 & 90 & 300 & 2.3 & 0.04 & 1.3 & 5.2 \\
\hline
\end{tabular}

${ }^{\mathrm{a}}$ Without ultrasound irradiation, $60^{\circ} \mathrm{C}$. Recipe ( $f$. Exptl. part): $100 \mathrm{~g}$ water, $20 \mathrm{~g} \mathrm{BA}\left(=1.56 \mathrm{~mol} \cdot \mathrm{dm}^{-3}\right)$, $20 \mathrm{~g} \mathrm{SDS}$, and $0.025 \mathrm{~g} \mathrm{NaHCO}$, $[\mathrm{LPO}]=0.01 \mathrm{~mol} \cdot \mathrm{dm}^{-3}$. 1) The first maximal rate/conversion data, 2) The second maximal rate/conversion data. 3) The size and number of final polymer particles, 4) The size and number of monomer droplets, Conv.f - final conversion.

Table IV. Kinetic, molecular weight and colloidal parameters in the emulsion polymerization of BA (with ultrasound irradiation) ${ }^{\mathrm{a}}$

\begin{tabular}{|c|c|c|c|c|c|c|c|c|c|}
\hline \multirow[t]{2}{*}{$\begin{array}{l}\text { Temp. } \\
\left({ }^{\circ} \mathrm{C}\right)\end{array}$} & \multicolumn{2}{|c|}{$\begin{array}{l}R_{\mathrm{p}, \max } \times 10^{3} / \mathrm{Conv}_{\cdot R \mathrm{p}, \max } \\
\quad\left(\mathrm{mol} \cdot \mathrm{dm}^{-3} \cdot \mathrm{s}^{-1}\right) /(\%)\end{array}$} & \multirow[t]{2}{*}{$\begin{array}{l}\text { Conv.f } \\
(\%)\end{array}$} & \multicolumn{2}{|c|}{$\begin{array}{c}D \\
(\mathrm{~nm})\end{array}$} & \multicolumn{2}{|c|}{$\begin{array}{c}N_{\mathrm{p}} 10^{-17} \\
\left(\mathrm{dm}^{3}\right)\end{array}$} & \multirow[t]{2}{*}{$M_{\mathrm{v}} \times 10^{-6}$} & \multirow[t]{2}{*}{$\begin{array}{c}\bar{n} \times 10^{2} \\
\left(\text { particle }^{-1}\right)\end{array}$} \\
\hline & 1) & 2) & & 3) & 4) & 3) & 4) & & \\
\hline 50 & $2.0 / 15$ & & 97 & 86 & - & 5.7 & - & 2.6 & 3.8 \\
\hline 55 & $2.5 / 16$ & $0.3 / 45$ & 88 & 78 & - & 6.9 & - & 2.5 & 3.7 \\
\hline 60 & $2.4 / 14$ & $0.6 / 47$ & 81 & 75 & - & 7.1 & - & 2.3 & 3.3 \\
\hline 65 & $3.0 / 12$ & $1.2 / 45$ & 91 & 70 & - & 9.8 & - & 2.1 & 2.8 \\
\hline 70 & $3.2 / 10$ & $2.5 / 50$ & 92 & 68 & 180 & 10.0 & 0.08 & 2.1 & 2.6 \\
\hline 75 & $1.5 / 20$ & & 89 & 62 & 200 & 12.5 & 0.04 & 2.0 & 0.9 \\
\hline 80 & & & 94 & 60 & 150 & 14.5 & 0.03 & 2.0 & \\
\hline
\end{tabular}

${ }^{a}$ With ultrasound irradiation, $60^{\circ} \mathrm{C}$. Recipe ( $c f$. Exptl. part or the legend to Table I). $[\mathrm{BA}]=1.56 \mathrm{~mol} \cdot \mathrm{dm}^{-3}$, $\left.[\mathrm{LPO}]=0.01 \mathrm{~mol} \cdot \mathrm{dm}^{-3}, 60^{\circ} \mathrm{C} .1-4\right)$ See the legend to Table I.

Table V. Variation of kinetic, molecular weight and colloidal parameters in the microemulsion polymerization of BA with $[\mathrm{LPO}]^{\mathrm{a}}$

\begin{tabular}{rccccccc}
\hline $\begin{array}{c}{[\mathrm{LPO}] 10^{3}} \\
\left(\mathrm{~mol} \cdot \mathrm{dm}^{-3}\right)\end{array}$ & $\begin{array}{c}R_{\mathrm{p}, \max } 10^{3} / \mathrm{Conv} \cdot \max \\
\left(\mathrm{mol} \cdot \mathrm{dm}^{-3} \cdot \mathrm{s}^{-1}\right) /(\%)\end{array}$ & $\begin{array}{c}\mathrm{Conv}_{\cdot f} \\
(\%)\end{array}$ & $\begin{array}{c}D \\
(\mathrm{~nm})\end{array}$ & $\begin{array}{c}N_{\mathrm{p}} \times 10^{-17} \\
\left(\mathrm{dm}^{3}\right)\end{array}$ & $M_{\mathrm{v}} \times 10^{-6}$ & $\begin{array}{c}\bar{n} \times 10^{2} \\
\left(\mathrm{particle}^{-1}\right)\end{array}$ \\
\hline $1.0^{\mathrm{b}}$ & $0.6 / 25$ & - & 89 & 95 & 3.8 & 2.3 & 1.5 \\
$2.5^{\mathrm{b}}$ & $0.74 / 7$ & $0.87 / 63$ & 90 & 92 & 4.3 & 2.2 & 1.7 \\
$5.0^{\mathrm{b}}$ & $1.5 / 11$ & $1.2 / 51$ & 91 & 90 & 4.4 & 2.4 & 3.2 \\
$10.0^{\mathrm{b}}$ & $2.4 / 17$ & $1.7 / 42$ & 93 & 85 & 4.5 & 2.4 & 4.2 \\
$1.0^{\mathrm{c}}$ & $1.95 / 12$ & - & 96 & 89 & 5.0 & 2.2 & 3.8 \\
$5.0^{\mathrm{c}}$ & $2.1 / 15$ & - & 92 & 77 & 7.8 & 2.2 & 2.7 \\
$10.0^{\mathrm{c}}$ & $2.4 / 14$ & $0.6 / 47$ & 81 & 75 & 7.1 & 2.3 & 3.3 \\
\hline
\end{tabular}

${ }^{\text {a }}$ Recipe ( $c f$. Exptl. part or the legend to Table III), $60{ }^{\circ} \mathrm{C}$. ${ }^{\mathrm{b}}$ Without ultrasound irradiation, ${ }^{\mathrm{c}}$ with ultrasound irradiation. $\left.[\mathrm{BA}]=1.56 \mathrm{~mol} \cdot \mathrm{dm}^{-3} \cdot 1-2\right)$ See the legend to Table III.

observed in the NMEP but the increase in the polymerization rate with increasing temperature was less pronounced. Furthermore, the maximal rates were larger in the CMEP than in the NMEP. In the NMEP, the decrease in the polymerization rate was already observed above $70^{\circ} \mathrm{C}$. The first maximum rates of polymerization were used to get the Arrhenius plot $\left(\ln R_{\mathrm{p}} v s .1 / T\right.$, where $T$ is absolute temperature in ${ }^{\circ} \mathrm{K}$,
Tables I and II) and the overall activation energy $\left(E_{\mathrm{o}}\right)$ :

$$
\begin{aligned}
& E_{\mathrm{o}}(\mathrm{CMEP})=84 \mathrm{~kJ} \cdot \mathrm{mol}^{-1} ; \\
& E_{\mathrm{o}}(\mathrm{NMEP})=20 \mathrm{~kJ} \cdot \mathrm{mol}^{-1}
\end{aligned}
$$

The overall activation energy for the solution $\left(E_{\mathrm{o}, \mathrm{sol}}\right)$ and emulsion $\left(E_{\mathrm{o}, \mathrm{emul}}\right)$ polymerization can be expressed as follows: ${ }^{36}$ 


$$
\begin{aligned}
& E_{\mathrm{o}, \text { sol }}=E_{\mathrm{p}}-0.5 E_{\mathrm{t}}+0.5 E_{\mathrm{d}} \\
& E_{\mathrm{o}, \text { emul }}=0.6 E_{\mathrm{p}}+0.4 E_{\mathrm{d}}
\end{aligned}
$$

where $E_{\mathrm{p}}$ is the activation energy for propagation, $E_{\mathrm{t}}$ the activation energy for termination and $E_{\mathrm{d}}$ the activation energy for decomposition of initiator. For most monomers, $E_{\mathrm{p}}, E_{\mathrm{t}}$, and $E_{\mathrm{d}}$ are 30,20 , and 125 $\mathrm{kJ} \mathrm{mol}^{-1}$, respectively. ${ }^{37}$ Using eqs 9 and 10 , the overall activation energy is estimated to be $c a .90 \mathrm{~kJ} \mathrm{~mol}^{-1}$ for solution or bulk polymerization and $c a$. $70 \mathrm{~kJ} \mathrm{~mol}^{-1}$ for emulsion polymerization, respectively. $E_{\mathrm{o}, \text { sol }}$ for the solution polymerization of BA was estimated to be $c a .80-100 \mathrm{~kJ} / \mathrm{mol}^{-1} \cdot{ }^{37}$ In the polymerization of BA and styrene initiated by DBP, AIBN and APS in the microemulsion droplets $E_{\mathrm{o}}$ was determined to be $85 \mathrm{~kJ} \cdot \mathrm{mol}^{-1} \cdot{ }^{20,38} E_{\mathrm{o}, \mathrm{emul}}$ for the emulsion polymerization of styrene was reported to be $60 \mathrm{~kJ} /$ $\mathrm{mol}^{-1} \cdot{ }^{39}$ The literature data show that the activation energy of the solution polymerization is somewhat larger than the activation energy of the emulsion polymerization. Thus, this approach cannot be used to explain the large difference between activation energies of CMEP and NMEP.

The strong deviation from the classical approach is found in the microemulsion polymerization (NMEP) of $\mathrm{BA}$ proceeding under ultrasonic radiation $\left(E_{\mathrm{O}}=\right.$ $20 \mathrm{~kJ} \cdot \mathrm{mol}^{-1}$ ). The slight increase of the polymerization rate with temperature indicates the dominant effect of ultrasound irradiation on the polymerization. The ultrasonic irradiation can increase the decomposition of initiator and the exchange of reactants within the reaction system.

The rate of microemulsion polymerization of BA increases with increasing the DBP concentration and the increase is much less pronounced with the ultrasound irradiation or the rate of polymerization even decreases with increasing the initiator concentration (Tables I and II, Ref 19 and Ref 20):

$$
\begin{aligned}
& R_{\mathrm{p}} \propto[\mathrm{DBP}]^{0.35} \text { and } R_{\mathrm{p}, \mathrm{u}} \propto[\mathrm{DBP}]^{0.11} \\
& \quad\left([\mathrm{BA}]=1.56 \mathrm{~mol} \cdot \mathrm{dm}^{-3}\right) \\
& R_{\mathrm{p}} \propto[\mathrm{DBP}]^{0.35} \text { and } R_{\mathrm{p}, \mathrm{u}} \propto[\mathrm{DBP}]^{-0.17} \\
& \quad\left([\mathrm{BA}]=1.17 \mathrm{~mol} \cdot \mathrm{dm}^{-3}\right)
\end{aligned}
$$

The similar behavior was observed in the microemulsion polymerization of BA initiated by LPO. The rate of polymerization increases with increasing the LPO concentration and the increase is much less pronounced in the runs with ultrasound irradiation (Table V):

$$
\begin{aligned}
& R_{\mathrm{p}} \propto[\mathrm{LPO}]^{0.63} \text { and } R_{\mathrm{p}, \mathrm{u}} \propto[\mathrm{LPO}]^{0.08} \\
& \quad\left([\mathrm{BA}]=1.56 \mathrm{~mol} \cdot \mathrm{dm}^{-3}\right)
\end{aligned}
$$

Under the ultrasound irradiation, the polymerization rate $\left(R_{\mathrm{p}, \mathrm{u}}\right)$ is nearly independent of [LPO]. The transfer of the ultrasonic energy to heat should cause the stronger increase in the overall polymerization rate with increasing [LPO]. The data show that the reverse is true. The dissolution or re-organization of microdroplets by the ultrasound irradiation might vary the number of active reaction loci as the reaction proceeds.

\section{Colloidal and Molecular Weight Parameters}

The final particle size $(D / \mathrm{nm})$ decreases and the number of latex particles $\left(N_{\mathrm{p}} / \mathrm{dm}^{-3}\right)$ increases with increasing temperature or the rate of initiation $\left(R_{\mathrm{i}}\right)$ (Tables III and IV). The rate of production of radicals or particles increases with increasing temperature. In this approach the concentration of initiator (DBP or LPO) is kept constant. The value of $R_{\mathrm{i}}=2 f k_{\mathrm{d}}$ [I] was varied simply by changing the reaction temperature from 50 to $80^{\circ} \mathrm{C}$ ( $f$ is the initiator efficiency $\left(c a .0 .6^{40}\right), k_{\mathrm{d}}$ is the initiator decomposition rate constant ${ }^{41}$ and [I] is the initiator concentration). The number of final polymer particles was observed to increase with temperature (or $\rho_{\mathrm{i}}$ ) and the increase is much less pronounced with the ultrasound irradiation:

$$
N_{\mathrm{p}} \propto \rho_{\mathrm{i}}^{0.41} \text { and } N_{\mathrm{p}, \mathrm{u}} \propto \rho_{\mathrm{i}}^{0.14} \quad \text { (for LPO runs) }
$$

The value $x_{\mathrm{CMEP}}=0.41$ (for the CMEP) is in a good agreement with the micellar model $(x=0.4)$. Furthermore, the value $x=0.41$ is much larger than 0.11 and 0.28 for the miniemulsion and emulsion polymerization of MMA. ${ }^{42}$ On the contrary, $x_{\mathrm{NMEP}}=0.14$ is between 0.11 and 0.28. Delgado et al. ${ }^{3}$ found the opposite relationship in his copolymerization work with vinyl acetate and butyl acrylate. For emulsions, the order was found to be 0.0 , and for miniemulsions 0.8 . The data presented for miniemulsion indicate a leveling of particle number at high initiator concentration. This is believed to correspond to the point in which all monomer droplets become nucleated. This can be a case in the NMEP system where the dissolution of monomer droplets decreases the number of stable monomer droplets.

Variations of number of polymer particles were observed to be a complex function of initiator type and reaction conditions (with or without ultrasound). In the DBP-initiated polymerization the ultrasound strongly depressed the dependence of particle rate formation on the initiator concentration:

$$
\begin{aligned}
& N_{\mathrm{p}} \propto[\mathrm{DBP}]^{0.19} \text { and } N_{\mathrm{p}, \mathrm{u}} \propto[\mathrm{DBP}]^{-0.13} \\
& \quad\left([\mathrm{BA}]=1.17 \mathrm{~mol} \cdot \mathrm{dm}^{-3}\right)
\end{aligned}
$$

and

$$
\begin{aligned}
& N_{\mathrm{p}} \propto[\mathrm{DBP}]^{0.16} \text { and } N_{\mathrm{p}, \mathrm{u}} \propto[\mathrm{DBP}]^{0.0} \\
& \quad\left([\mathrm{BA}]=1.56 \mathrm{~mol} \cdot \mathrm{dm}^{-3}\right)
\end{aligned}
$$


The particle rate formation was somewhat less efficient in the LPO-initiated polymerization than in the DBP-initiated one. The number of particles is nearly independent of LPO concentration. The ultrasound somewhat increased the particle nucleation rate:

$$
N_{\mathrm{p}} \propto[\mathrm{LPO}]^{0.05} \text { and } N_{\mathrm{p}, \mathrm{u}} \propto[\mathrm{LPO}]^{0.17}
$$

The particle concentration variations indicate that the increased exchange of reaction components caused by the ultrasound irradiation depresses the nucleation of polymer particles.

The viscosity-average molecular weights slightly decrease with increasing temperature (or $R_{\mathrm{i}}$, Tables III and IV):

$$
M_{\mathrm{v}} \propto R_{\mathrm{i}}^{-0.1} \text { and } M_{\mathrm{v}, \mathrm{u}} \propto R_{\mathrm{i}}^{-0.07}
$$

The slight variation in $M_{\mathrm{v}}$ disfavours any effect of ultrasound on the bimolecular termination of radicals.

The initial stage of microemulsion polymerization is accompanied by the abrupt increase in turbidity due to accumulation of polymer in the microdroplets. ${ }^{2}$ This behavior was observed in the CMEP as well as in NMEP where the diameter of initially formed particles is $c a$. $200-400 \mathrm{~nm}$. The very large polymer particles, however, were not found in the final polymer dispersions. The very large monomer-swollen polymer particles can not compete with microdroplets for entering radicals and, therefore, they mainly act as a monomer-reservoir.

The rate of microemulsion polymerization is observed to increase with increasing initiator concentration. ${ }^{2}$ The increase in polymerization rate is attributed to the increased number of active latex particles and average number of radicals per particle. The addition of hydrophobe was found to increase the droplet size, droplet agglomeration and phase separation in the microemulsion systems. This was attributed to the transformation of the thermodynamically stable (transparent) microemulsion to miniemulsion or emulsion. The increased turbidity in the microemulsion caused by the accumulation of hydrophobe (LPO-derived
Table VI. Kinetic parameters for emulsion polymerization of BA

\begin{tabular}{lll}
\hline \multicolumn{1}{c}{ Parameter } & \multicolumn{1}{c}{ Numerical value } & Ref. \\
\hline$[\mathrm{BuA}]_{\mathrm{p}}$ & $2.35 \mathrm{~mol} \mathrm{dm}^{-3}$ & 43 \\
$k_{\mathrm{d}, \mathrm{DBP}}\left(50^{\circ} \mathrm{C}\right)$ & $2.83 \times 10^{-6} \mathrm{~s}^{-1}$ & 41 \\
$k_{\mathrm{d}, \mathrm{LPO}}$ & $6.62 \times 10^{17} \exp \left(-140167 / \mathrm{RT}^{-1} \mathrm{~s}^{-1}\right.$ & 41 \\
$k_{\mathrm{p}}$ & $7.37 \times 10^{5} \exp (-1157 / \mathrm{T}) \mathrm{L} \mathrm{mol}^{-1} \mathrm{~s}^{-1}$ & 44 \\
$k_{\mathrm{t}}$ & $17.13 \times 10^{9} \exp (-1083 / \mathrm{T}) \mathrm{L} \mathrm{mol}^{-1} \mathrm{~s}^{-1}$ & 45,46 \\
$k_{\mathrm{fm}}$ & $2.9 \times 10^{5} \exp (-3921 / \mathrm{T}) \mathrm{L} \mathrm{mol}^{-1} \mathrm{~s}^{-1}$ & 47 \\
$m_{\mathrm{d}}$ & $1 / 1050$ & 45 \\
$D_{\mathrm{c}}$ & $4.1 \times 10^{-5} \mathrm{~cm}^{2} \mathrm{~s}^{-1}$ & 45 \\
$D_{\mathrm{p}}$ & $8.66 \times 10^{-7} \mathrm{~cm}^{2} \mathrm{~s}^{-1}$ & 48 \\
$\mathrm{C}_{\mathrm{w}}$ & $6.4 \times 10^{-3} \mathrm{~mol} \mathrm{dm}^{-3}$ & 49 \\
\hline
\end{tabular}

oligomers) can be discussed in terms of the re-organization of monomer droplets.

\section{The Fate of Radicals}

Tables I-V show that the $\bar{n}$ is much below 0.5 which indicates the strong desorption of monomeric radicals from particles. The chain transfer to monomer and desorption of monomeric radicals from the polymer particles decreases the concentration of radicals in the polymer particles. In the conventional (CMEP) emulsion polymerization the $\bar{n}$ increases with temperature up to $c a .65^{\circ} \mathrm{C}$ and then $\bar{n}$ slightly decreases (Table III). Under the ultrasound conditions the $\bar{n}$ decreases with increasing the temperature in the whole temperature range (Table IV). The $\bar{n}$ value increases with increasing the LPO and DBP concentration (CMEP) (Tables I, II and V). Under the ultrasound irradiation the $\bar{n}$ value decreases with increasing the LPO and DBP concentration (Tables I, II and V).

The estimated desorption kinetic data and the kinetic parameters for the calculation of entry and exit events of radicals are listed in Tables VI-X.

In the DBP-initiated microemulsion polymerization of BA (Table VII) without ultrasound the iterative approach estimates the increase in $k_{\text {des }}^{\prime}$ with increasing the DBP concentration. This can be caused by the partitioning of primary radicals derived from DBP be-

\begin{tabular}{|c|c|c|c|c|c|c|c|c|c|c|}
\hline \multirow[t]{2}{*}{$\begin{array}{l}{[\mathrm{DBP}] 10^{3}} \\
\left(\mathrm{~mol} \mathrm{dm}^{-3}\right)\end{array}$} & \multirow[t]{2}{*}{$a \times 10^{4}$} & \multirow[t]{2}{*}{$m \times 10^{2}$} & \multicolumn{3}{|c|}{$\begin{array}{c}k_{\mathrm{des}} \\
\left(\mathrm{s}^{-1}\right)\end{array}$} & \multicolumn{3}{|c|}{$\begin{array}{c}k_{\text {des }}^{\prime} \times 10^{11} \\
\left(\mathrm{~cm}^{2} \mathrm{~s}^{-1}\right)\end{array}$} & \multirow{2}{*}{$\begin{array}{c}\rho_{\mathrm{a}} \\
\left(\mathrm{mol} \mathrm{dm}^{-3} \mathrm{~s}^{-1}\right) \\
1)\end{array}$} & \multirow[t]{2}{*}{$\rho_{\mathrm{a}} / \rho_{\mathrm{i}}$} \\
\hline & & & 1) & 2) & 3) & 1) & 2) & 3) & & \\
\hline $0.71^{b}$ & 1.30 & 0.17 & 6.35 & 1.79 & 0.15 & 0.27 & 7.64 & 0.64 & 0.12 & 26.58 \\
\hline $1.0^{\mathrm{b}}$ & 1.66 & 0.40 & 14.81 & 1.84 & 0.16 & 0.61 & 7.64 & 0.64 & 0.22 & 35.09 \\
\hline $10.0^{\mathrm{b}}$ & 7.22 & 0.49 & 27.30 & 2.4 & 0.2 & 0.87 & 7.64 & 0.64 & 0.76 & 18.96 \\
\hline $0.71^{\mathrm{c}}$ & 0.51 & 0.02 & 0.84 & 2.4 & 0.2 & 0.03 & 7.64 & 0.64 & 0.03 & 12.64 \\
\hline $1.0^{\mathrm{c}}$ & 0.84 & 0.05 & 2.42 & 2.33 & 0.19 & 0.08 & 7.64 & 0.64 & 0.08 & 16.97 \\
\hline $2.5^{\mathrm{c}}$ & 2.9 & 0.17 & 7.34 & 2.04 & 0.17 & 0.28 & 7.64 & 0.64 & 0.22 & 17.43 \\
\hline $10.0^{\mathrm{c}}$ & 15.6 & 1.11 & 43.0 & 1.88 & 0.16 & 1.74 & 7.64 & 0.64 & 1.17 & 19.40 \\
\hline
\end{tabular}

Table VII. Variation of desorption rate coefficient in the emulsion polymerization of BA with the DBP concentration $^{\mathrm{a}}$

${ }^{\mathrm{a}}$ Other details see in the legend to Table IV. ${ }^{\mathrm{b}}$ Without ultrasound irradiation, ${ }^{\mathrm{c}}$ with ultrasound irradiation. 1) Ugelstadt model, 2) Nomura model, 3) Gilbert model. 
Table VIII. Variation of desorption rate coefficient in the emulsion polymerization of BA with reaction temperature ${ }^{\mathrm{a}}$

\begin{tabular}{|c|c|c|c|c|c|c|c|c|c|c|}
\hline \multirow[t]{2}{*}{$\begin{array}{c}T \\
\left({ }^{\circ} \mathrm{C}\right)\end{array}$} & \multirow[t]{2}{*}{$a \times 10^{4}$} & \multirow[t]{2}{*}{$m \times 10^{2}$} & \multicolumn{3}{|c|}{$\begin{array}{c}k_{\mathrm{des}} \\
\left(\mathrm{s}^{-1}\right)\end{array}$} & \multicolumn{3}{|c|}{$\begin{array}{c}k_{\text {des }}^{\prime} \times 10^{11} \\
\left(\mathrm{~cm}^{2} \cdot \mathrm{s}^{-1}\right)\end{array}$} & \multirow{2}{*}{$\begin{array}{c}\rho_{\mathrm{a}} \\
\left(\mathrm{mol} \cdot \mathrm{dm}^{-3} \cdot \mathrm{s}^{-1}\right) \\
1)\end{array}$} & \multirow{2}{*}{$\begin{array}{c}\rho_{\mathrm{a}} / \rho_{\mathrm{i}} \\
1)\end{array}$} \\
\hline & & & 1) & 2) & 3) & 1) & 2) & 3) & & \\
\hline 50 & 1.93 & 26.3 & 585.0 & 1.45 & 0.12 & 34.3 & 8.50 & 0.72 & 11.42 & 26.61 \\
\hline 55 & 2.25 & 10.2 & 310.6 & 1.97 & 0.16 & 15.27 & 9.69 & 0.82 & 10.67 & 15.55 \\
\hline 60 & 3.70 & 9.8 & 336.0 & 2.34 & 0.20 & 15.77 & 11.0 & 0.92 & 15.23 & 12.02 \\
\hline 65 & 6.09 & 8.5 & 364.5 & 2.99 & 0.25 & 15.16 & 12.43 & 1.04 & 23.23 & 8.84 \\
\hline 70 & 4.36 & 16.7 & 1125.0 & 4.40 & 0.37 & 35.81 & 14.02 & 1.17 & 42.14 & 14.34 \\
\hline 75 & 3.69 & 13.5 & 1509.1 & 6.73 & 0.56 & 35.29 & 15.73 & 1.31 & 57.90 & 14.03 \\
\hline 80 & 16.01 & 61.3 & 4521.4 & 3.34 & 0.29 & 143.9 & 17.60 & 1.47 & 312.99 & 9.67 \\
\hline
\end{tabular}

a Without ultrasound irradiation. Other details are shown in the legend to Figure 3. 1) $T_{\text {model }}$, Ugelstadt/O'Tool approach, 2) $N_{\text {model }}$, Nomura model, 3) $G_{\text {model }}$, Gilbert model.

Table IX. Variation of desorption rate coefficient in the emulsion polymerization of $\mathrm{BA}^{\mathrm{a}}$

\begin{tabular}{|c|c|c|c|c|c|c|c|c|c|c|}
\hline \multirow[t]{2}{*}{$\begin{array}{c}T \\
\left({ }^{\circ} \mathrm{C}\right)\end{array}$} & \multirow[t]{2}{*}{$a \times 10^{4}$} & \multirow[t]{2}{*}{$m \times 10^{2}$} & \multicolumn{3}{|c|}{$\begin{array}{l}k_{\mathrm{des}} \\
\left(\mathrm{s}^{-1}\right)\end{array}$} & \multicolumn{3}{|c|}{$\begin{array}{c}k_{\text {des }}^{\prime} \times 10^{11} \\
\left(\mathrm{~cm}^{2} \mathrm{~s}^{-1}\right)\end{array}$} & \multirow{2}{*}{$\begin{array}{c}\rho_{\mathrm{a}} \\
\left(\mathrm{mol} \cdot \mathrm{dm}^{-3} \mathrm{~s}^{-1}\right) \\
1)\end{array}$} & \multirow{2}{*}{$\begin{array}{c}\rho_{\mathrm{a}} / \rho_{\mathrm{i}} \\
1)\end{array}$} \\
\hline & & & 1) & 2) & 3) & 1) & 2) & 3) & & \\
\hline 50 & 0.88 & 2.7 & 82.6 & 1.77 & 0.15 & 3.97 & 8.5 & 0.72 & 3.42 & 13.05 \\
\hline 55 & 1.11 & 3.8 & 158.9 & 2.45 & 0.20 & 6.28 & 9.69 & 0.81 & 6.40 & 13.40 \\
\hline 60 & 2.00 & 8.7 & 434.1 & 3.00 & 0.25 & 15.8 & 10.00 & 0.92 & 15.23 & 15.24 \\
\hline 65 & 2.37 & 14.1 & 907.4 & 3.91 & 0.33 & 28.9 & 12.43 & 1.04 & 21.32 & 17.74 \\
\hline 70 & 3.90 & 27.5 & 2022.6 & 4.67 & 0.39 & 60.8 & 14.02 & 1.17 & 55.31 & 19.28 \\
\hline 75 & 4.49 & 112.5 & 5320.2 & 6.30 & 0.53 & 678.1 & 15.73 & 1.31 & 250.92 & 55.08 \\
\hline
\end{tabular}

${ }^{a}$ With ultrasound irradiation. Other details are shown in the legend to Figure 5. 1) $T_{\text {model }}, 2$ ) $\mathrm{N}_{\text {model }}, 3$ ) $\mathrm{G}_{\text {model }}$.

Table X. Variation of desorption rate coefficient in the radical polymerization of BA with LPO concentration ${ }^{\mathrm{a}}$

\begin{tabular}{|c|c|c|c|c|c|c|c|c|c|c|}
\hline \multirow[t]{2}{*}{$\begin{array}{c}{[\mathrm{LPO}] 10^{3}} \\
\left(\mathrm{~mol} \cdot \mathrm{dm}^{-3}\right)\end{array}$} & \multirow[t]{2}{*}{$a \times 10^{6}$} & \multirow[t]{2}{*}{$m \times 10^{2}$} & \multicolumn{3}{|c|}{$\begin{array}{l}k_{\mathrm{des}} \\
\left(\mathrm{s}^{-1}\right)\end{array}$} & \multicolumn{3}{|c|}{$\begin{array}{c}k_{\text {des }}^{\prime} \times 10^{11} \\
\left(\mathrm{~cm}^{2} \cdot \mathrm{s}^{-1}\right)\end{array}$} & \multirow{2}{*}{$\begin{array}{c}\rho_{\mathrm{a}} \\
\left(\mathrm{mol} \mathrm{dm}^{-3} \mathrm{~s}^{-1}\right) \\
1)\end{array}$} & \multirow[t]{2}{*}{$\rho_{\mathrm{a}} / \rho_{\mathrm{i}}$} \\
\hline & & & 1) & 2) & 3) & 1) & 2) & 3) & & \\
\hline $1.0^{\mathrm{b}}$ & 17.36 & 3.6 & 80.19 & 1.3 & 0.11 & 4.70 & 7.54 & 0.64 & 1.25 & 32.53 \\
\hline $2.5^{\mathrm{b}}$ & 35.40 & 6.0 & 148.3 & 1.39 & 0.12 & 8.15 & 7.64 & 0.64 & 2.58 & 29.76 \\
\hline $5.0^{\mathrm{b}}$ & 61.38 & 2.9 & 75.57 & 1.45 & 0.12 & 3.98 & 7.64 & 0.64 & 2.54 & 15.86 \\
\hline $10.0^{\mathrm{b}}$ & 85.25 & 0.15 & 4.80 & 1.63 & 0.14 & 0.23 & 7.64 & 0.64 & 3.18 & 12.02 \\
\hline $1.0^{\mathrm{c}}$ & 10.88 & 0.35 & 9.63 & 1.49 & 0.13 & 0.50 & 7.64 & 0.64 & 0.39 & 13.30 \\
\hline $5.0^{c}$ & 23.81 & 1.5 & 62.81 & 1.98 & 0.17 & 2.42 & 7.64 & 0.64 & 1.82 & 18.28 \\
\hline $10.0^{c}$ & 46.19 & 2.0 & 90.56 & 2.09 & 0.18 & 3.31 & 7.64 & 0.64 & 3.18 & 15.24 \\
\hline
\end{tabular}

${ }^{\mathrm{a}}$ Other details see in the legend to Table III. ${ }^{\mathrm{b}}$ Without ultrasound irradiation, ${ }^{\mathrm{c}}$ with ultrasound irradiation. 1) Ugelstadt model, 2) Nomura model, 3) Gilbert model.

tween the oil and water phases. For the $\mathrm{N}_{\text {model }}$ and $\mathrm{G}_{\text {model }}$ value of $k_{\text {des }}^{\prime}$ remains constant for all the initiator concentrations. These models don't comprise value for initiator concentration in their equations and final value of desorption constant can only be influenced by change of temperature for given monomer.

The exit (desorption) rate constant $k_{\text {des }}^{\prime}\left(\mathrm{cm}^{2} \mathrm{~s}^{-1}\right)$ and $k_{\text {des }}\left(\mathrm{s}^{-1}\right)$ (Ugelstadt/O'Tool approach, Nomura model and Gilbert model) as a function of temperature for the CMEP and NMEP initiated by LPO are summarized in Tables VIII and IX. The values of $k_{\text {des }}$ $\left(\mathrm{s}^{-1}\right)$ and $k_{\text {des }}^{\prime}\left(\mathrm{cm}^{2} \mathrm{~s}^{-1}\right)$ are somewhat larger under the ultrasound conditions. The increased degradation of micellar aggregates by ultrasound irradiation some- what increases desorption of monomer radicals. The $k_{\text {des }}^{\prime}\left(\mathrm{cm}^{2} \mathrm{~s}^{-1}\right)$ slightly increases with increasing the reaction temperature (except for the highest and lowest temperatures for $T_{\text {model }}$ ). The increase in desorption rate with temperature can be attributed to the formation of smaller particles with increasing the reaction temperature.

The radical entry rate $\left(\rho_{\mathrm{a}}\right)$ estimated by the $T_{\text {model }}$ increases with increasing the reaction temperature. The $\rho_{\mathrm{a}} / \rho_{\mathrm{i}}$ ratio decreases with increasing temperature for the CMEP but increases for the NMEP. Thus, the degradation of microdroplets probably decreases the accumulation of radicals in the polymer particles. The formation of loosely-packed microdroplets in 
the NMEP disfavour the immobilization of monomer radicals within the particles. For the classical emulsion polymerization the $\rho_{\mathrm{a}} / \rho_{\mathrm{i}}$ ratio is found to be close to 1 . The large deviation of the $\rho_{\mathrm{a}} / \rho_{\mathrm{i}}$ ratio from 1 can result from the overestimation of $k_{\text {des }}^{\prime}$. Furthermore, the hydrophobic initiator can also contribute to the deviation. The oil soluble initiator LPO is located in the microdroplets and the primary radicals derived from LPO cannot take part in the desorption events.

Ugelstad et al. ${ }^{27}$ solved the simultaneous eqs 6 and 7 for $\bar{n}_{\text {theor }}$ and plotted the calculated $\bar{n}_{\text {theor }}$ 's against the value of $a_{1}$ at fixed value of Y, varying the value of $m$ as a parameter. For the emulsion polymerization of styrene the value of $m$ is about $10^{-4}$ or smaller. The values of $m$ for the microemulsion polymerization of BA are $c a$. by one order in the magnitude larger ( $c a$. about $10^{-3}$, Tables VII-X) which indicates a increased desorption of monomeric radicals from the polymer particles. The values of $m$ and $a$ (their position in the $\bar{n}_{\text {theor }} v s$. $a_{1}$ plot $^{27}$ ) suggest the desorption of monomeric radicals from the particles and the compartmentalized nature of the reaction loci.

The $k_{\text {des }}^{\prime}$ (Tables VIII and IX) for different models differs by one or two orders in the magnitude. The smallest $k_{\text {des }}^{\prime}$ presents the dynamic model $\left(\mathrm{G}_{\text {model }}\right)$. The iterative approach suggests a less intensive desorption of monomeric radicals than the Nomura model. The value of $k_{\text {des }}^{\prime}$ increases in the following order:

$$
\mathrm{G}_{\text {model }}<\mathrm{N}_{\text {model }}<T_{\text {model }}
$$

The model of desorption of radicals has the following steps: ${ }^{31} 1$ ) transfer of free radical activity to monomer, 2) diffusion of the resulting monomeric radical, or small oligomeric, free radical to the particle surface, and then, if propagation beyond a certain degree of polymerization has not occurred, 3 ) diffusion of the free radical species away from the particle through the aqueous phase. The rate limiting step for the exit of radicals from present relatively large particles is the diffusion of monomeric radicals to the particle surface. The surface active BA monomer is known to concentrate in the interfacial layer due to which increases the contribution of the polymerization in the upper spheres of polymer particles. ${ }^{3}$ Under such conditions the chain transfer to emulsifier and then the exit of both the monomeric and emulsifier radicals into the organic continuous phase can be operative.

The iterative approach estimates the decrease in the $k_{\text {des }}^{\prime}$ for the CMEP and increase in the $k_{\text {des }}^{\prime}$ for the NCMEP with increasing the initiator concentration (Tables VII and X). Thus, the ultrasound irradiation initiates the desorption (or deactivation) of radicals in the LPO-initiated polymerization. The increased degradation of close-packing emulsifier layer or micellar aggregates disfavors the growth events or im- mobilization of radicals in the particles.

The radical entry rate $\left(\rho_{\mathrm{a}}\right)$ parameter increases with increasing the LPO and DBP concentration and the $\rho_{\mathrm{a}}$ is somewhat larger in CMEP. The $\rho_{\mathrm{a}}$ is larger for the LPO-initiated emulsion than for DBP-initiated one. The absence of LPO-derived primary radicals in the aqueous phase does not influence the water-phase termination due to which the larger fraction of monomeric radicals enters the particles. The ratio $\rho_{\mathrm{a}} / \rho_{\mathrm{i}}$ decreases with increasing the initiator concentration in CMEP. This results from the increase of $\rho_{\mathrm{i}}$ with increasing the initiator concentration. The reverse trend is observed in the NMEP. The ultrasound irradiation, thus, somehow suppresses the concentration of primary radicals. This can result from the increased bimolecular termination of primary (derived from the initiator) radicals and monomeric radicals caused by the increased de-organization of micellar aggregates.

According to the micellar model the initiation of emulsion polymerization is a two-step process. The first step starts in the continuous phase by the formation of primary radicals by the decomposition of the initiator. The reaction of primary radicals with monomer (soluble in the continuous phase) leads to the formation of oligomeric radicals. The second step occurs by the entry of oligomeric radicals into the monomer swollen micelles or polymer particles. The oligomeric radicals enter the polymer particles when they reach the hydrophobicity (or hydrophilicity) similar to that of the polymer particle. According to this assumption the hydrophobic primary radicals (derived from DBP) can enter the hydrophobic polymer particles. At the steady state, the overall rate of radical entry into particles $\rho_{\text {overall }}$ is expressed by

$$
\rho_{\text {overall }}=R_{\text {prod,w }}+R_{\text {des }}-R_{\text {ter,w }}
$$

where $R_{\text {prod,w }}$ is the rate of radical production in the continuous phase, $R_{\text {des }}$ the rate of radical desorption from polymer particles and $R_{\text {ter,w }}$ and the rate of radical termination in the continuous phase. For the LPOinitiated emulsion polymerization of BA the steady state somewhat differs from the model (eq 11). The LPO and its radical fragments are located in the monomer droplets only. Thus, the two-step initiation can not appear through the partitioning of LPOderived primary radicals. This can be realized via the desorption/re-entry of monomeric radicals. Under this condition, the overall rate of radical entry into particles $\rho_{\text {overall }}$ can be expressed by

$$
\rho_{\text {overall }}=R_{\text {des }}-R_{\text {ter, } \mathrm{w}}
$$

The percolation is known to be operative in the emulsifier-rich micellar (microemulsion) systems. Under this condition the reactants including hydrophobic primary radicals can be transferred among particles and 
the overall rate of radical entry into particles can be expressed as

$$
\rho_{\text {overall }}=R_{\text {coll }}+R_{\text {des }}-R_{\mathrm{ter}, \mathrm{w}}
$$

The absence of the collision parameter in the kinetic models for the entry and exit of radicals can contribute to the observed deviation in the estimated parameters. Furthermore, the interparticle collision influences the radical entry events and therefore it can be responsible for the similar behaviour for initiators with different hydrophobicity and hydrophilicity.

\section{CONCLUSIONS}

The microemulsion polymerization (MEP) of butyl acrylate (BA) stabilized by ionic emulsifier and initiated by oil-soluble dibenzoyl peroxide (DBP) or lauroyl peroxide (LPO) initiators have been studied under conventional (without ultrasound irradiation, CMEP) and nonconventional (ultrasonic irradiation) (NMEP) conditions. The polymerization rate $v s$. conversion curve of the microemulsion polymerization of BA initiated by DBP was described by two nonstationary rate intervals. Four nonstationary rate intervals with two rate maxima appear in the microemulsion polymerization of BA initiated by LPO. The maximal rate of polymerization increases with temperature and the increase is much more pronounced under the conventional conditions. The overall activation energy is much larger under the conventional conditions $(=84$ $\left.\mathrm{kJ} \cdot \mathrm{mol}^{-1}\right)$ than under the ultrasound $\left(=20 \mathrm{~kJ} \cdot \mathrm{mol}^{-1}\right)$ conditions. The exit (desorption) rate constants $k_{\text {des }}^{\prime}$ $\left(\mathrm{cm}^{2} \mathrm{~s}^{-1}\right)$ and $k_{\text {des }}\left(\mathrm{s}^{-1}\right)$ estimated by Ugelstadt/ O'Tool ( $\left.T_{\text {model }}\right)$, Nomura $\left(\mathrm{N}_{\text {model }}\right)$ and Gilbert $\left(\mathrm{G}_{\text {model }}\right)$ vary with temperature and the initiator type and concentration and reaction conditions (CMEP and NMEP). The $k_{\text {des }}^{\prime}\left(\mathrm{cm}^{2} \mathrm{~s}^{-1}\right)$ slightly increases with increasing the reaction temperature (except for the highest and lowest temperatures estimated by $\left.T_{\text {model }}\right)$. The $k_{\text {des }}\left(\mathrm{s}^{-1}\right)$ and $k_{\text {des }}^{\prime}\left(\mathrm{cm}^{2} \mathrm{~s}^{-1}\right)$ are larger under the ultrasound conditions. The increased degradation of micellar aggregates by ultrasound irradiation is related to the decreased compartmentalization of radicals in the micellar aggregates and increased desorption of monomeric radicals from the particles. The interparticle collision is suggested to increase the transport of reactants including hydrophobic radicals between particles which leads to the similar behaviour between initiators with different hydrophobicity and hydrophilicity.

Acknowledgment. This research was supported by the Science and Technology Assistance Agency through Grants No. APVT-20-017304 and APVT51-013204.

\section{REFERENCES}

1. R. Zana, S. Yiv, C. Strazielle, and P. Lianos, J. Colloid Interface Sci., 80, 208 (1981).

2. I. Capek, Adv. Colloid Interface Sci., 80, 85 (1999).

3. J. Delgado, M. S. El-Aasser, C. A. Sileb, and J. W. Vanderhoff, J. Polym. Sci., Part A: Polym. Chem., 28, 777 (1990).

4. a) J. S. Guo, E. D. Sudol, J. W. Vanderhoff, and M. S. Elaasser, J. Polym. Sci., Part A: Polym. Chem., 30, 691 (1992).

b) J. S. Guo, E. D. Sudol, J. W. Vanderhoff, and M. S. Elaasser, J. Polym. Sci., Part A: Polym. Chem., 30, 703 (1992).

5. R. Leung and D. O. Shah, J. Colloid Interface Sci., 113, 484 (1986).

6. E. Graber, J. Lang, and R. Zana, Kolloid Z. Z. Polym., 237, 47 (1970).

7. S. Yiv and R. Zana, J. Colloid Interface Sci., 65, 286 (1978).

8. A. Djavanbakht, J. Lang, and R. Zana, J. Phys. Chem., 81, 2630 (1977).

9. G. Cooper, F. Grieser, and S. Biggs, J. Colloid Interface Sci., 184, 52 (1996).

10. P. Alexander, British Pat., 611, 830 (1948).

11. G. S. Goncharov, A. N. Levin, and G. D. Mikhailov, Plast. Massy, 6, 8 (1960).

12. S. Biggs and F. Grieser, Macromolecules, 28, 4877 (1995).

13. P. Kruus and J. Patraboy, J. Phys. Chem., 89, 3379 (1985).

14. T. J. Mason, “Advance in Sonochemistry," vol. 2, JAI Press, London, 1991.

15. J. R. Allegra and S. A. Hawley, J. Acoust. Soc. Am., 51, 1545 (1972).

16. D. J. McClements, J. Acoust. Soc. Am., 91, 849 (1992).

17. I. Capek, V. Juraničova, K. Ito, J. Barton, and J. M. Asua, Polym. Int., 43, 1 (1997).

18. T. Tanrisever, O. Okay, and I. C. Sonmezoglu, J. Appl. Polym. Sci., 61, 485 (1996).

19. P. Potisk and I. Capek, Angew. Makromol. Chem., 222, 125 (1994).

20. I. Capek and P. Potisk, Eur. Polym. J., 31, 1269 (1995).

21. I. Capek and W. Funke, Makromol. Chem., 191, 2549 (1990).

22. W. D. Harkins, J. Am. Chem. Soc., 69, 1428 (1947).

23. W. V. Smith and R. H. Ewart, J. Chem. Phys., 16, 592 (1948).

24. D. T. Birtwistle and D. C. Blackley, J. Chem. Soc. Faraday Trans. 1, 77, 413 (1981).

25. M. J. Ballard, R. G. Gilbert, and D. H. Napper, J. Polym. Sci., Polym. Lett. Ed., 19, 533 (1981).

26. M. Nomura, H. Harada, K. Nakagawara, W. Eguchi, and S. Nagata, J. Chem. Eng. Jpn., 4, 160 (1971).

27. J. Ugelstad, P. C. Mork, and J. O. Aassen, J. Polym. Sci., 5, 2281 (1967).

28. J. I. Toole, J. Appl. Polym. Sci., 9, 1291 (1965).

29. P. L. Tang, E. D. Sudol, C. A. Silebi, and M. S. El-Aasser, J. Appl. Polym. Sci., 43, 1059 (1991).

30. J. Ugelstad and P. C. Br. Mork, Polym. J., 2, 31 (1970).

31. J. S. Guo, M. S. El-Aasser, E. D. Sudol, H. J. Yue, and J. W. 
Vanderhoff, J. Colloid Interface Sci., 140, 175 (1990).

32. J. Delgado, M. S. El-Aasser, C. A. Silebi, J. W. Vanderhoff, and J. Guilot, J. Polym. Sci., Part B: Polym. Phys., 26, 1495 (1988).

33. S. Y. Lin, C. S. Chern, T. J. Hsu, C. T. Hsu, and I. Capek, Polymer, 42, 1481 (2001).

34. J. L. Reimers and F. J. Schork, J. Appl. Polym. Sci., 60, 251 (1996).

35. C. M. Miller, E. D. Sudol, C. A. Silebi, and M. S. El-Aasser, Macromolecules, 28, 2765 (1995).

36. G. Odian, "Principles of polymerization," 2nd ed., Wiley, New York, 1981.

37. J. Brandrup and H. Immergut, "Polymer Handbook," 3rd ed., John Wiley and Sons, Inc., New York, 1989.

38. J. S. Guo, M. S. Elaasser, and J. W. Vanderhoff, J. Polym. Sci., Part A: Polym. Chem., 27, 691 (1989).

39. C. S. Chern, S. Y. Lin, and T. J. Hsu, Polym. J., 31, 516 (1999).

40. L. E. Redington, J. Polym. Sci., 3, 503 (1948).

41. J. Brandrup, E. H. Immergut, and E. A. Grulke, "Polymer
Handbook," 4th ed., Willey-Interscience, New York, N.Y., 1999.

42. K. Fontenot and F. J. Schork, J. Appl. Polym. Sci., 49, 633 (1993).

43. S. C. J. Pierik, A. M. van Herk, C. Plessis, J. H. van Steenis, T. Loonen, and A. Bombeeck, Eur. Polym. J., 41, 1212 (2005).

44. S. Beuermann, D. A. Paquet, Jr., J. H. McMinn, and R. A. Hutchinson, Macromolecules, 29, 4206 (1996).

45. E. Ginsburger, F. Pla, C. Fonteix, S. Hoppe, S. Massebeuf, P. Hobbes, and P. Swaels, Chem. Eng. Sci., 58, 4493 (2003).

46. O. Kammona, P. Pladis, C. E. Frantzikinakis, and C. Kiparissides, Macromol. Chem. Phys., 204, 983 (2003).

47. S. Maeder and R. G. Gilbert, Macromolecules, 31, 4410 (1998).

48. C. F. Jasso, J. Valdéz, J. H. Pérez, and O. Laguna, J. Appl. Polym. Sci., 80, 1343 (2001).

49. E. M. Coen, S. Peach, B. Morrison, and R. G. Gilbert, Polymer, 45, 3595 (2004). 